GU J Sci, Part C, 6(4): 834-850 (2018)

Gazi Üniversitesi
Fen Bilimleri Dergisi
PART C: TASARIM VE TEKNOLOJI
http://dergipark.gov.tr/gujsc

\title{
Düşük Maliyetli GPS Tabanlı Otonom Bir İnsansız Kara Aracının Tasarımı ve Yapılması
}

\author{
Halit HÜLAKO ${ }^{1, *}$, Sadettin KAPUCU ${ }^{2, * *}$ \\ ${ }^{I}$ Fırat Üniversitesi, Mühendislik Fakültesi, Makine Mühendisliği Bölümü, 23000, Merkez/ELAZIĞ \\ ${ }^{2}$ Gaziantep Üniversitesi, Mühendislik Fakültesi, Makine Mühendisliği Bölümü, 27000, ŞehitKamil/GAZİANTEP
}

$\ddot{O} \mathbf{z}$

Makale Bilgisi

Bașvuru: 07/05/2018

Düzeltme: 10/07/2018

Kabul: $12 / 11 / 2018$

Anahtar Kelimeler

Varış Noktası

Navigasyon

IKA

GPS

Keywords

Waypoint

Navigation

$U G V$

$G P S$
Son yıllarda insansız araçlar araştırmacılar için oldukça popüler hale gelmiştir ve hala bu araçlar araştırmacılar ve mühendisler tarafından geliştirilmektedir. İnsansız araçlar yapması gereken görevi yardım almadan gerçekleştirebilecek bütün kabiliyetlere sahip olmalıdır. Bu çalışmada bir insansız kara aracının (IKKA) bulunduğu herhangi bir konumdan, belirtilen varış noktalarına (waypoints) gitmesi çalışılmıştır. Bu amaç için tasarlanan insansız kara aracında düşük maliyetli GPS (Global Positionin System) modülü ve elektronik pusula sensörü kullanılarak İKA' nın konumu belirlenmiştir. Denetim/karar verici olarak da bir mikrodenetleyiciden faydalanılmıştır. Platform olarakta bir RC (radio controlled) araç şasesi ve motorları kullanılmıştır. IKA, mikrodenetleyiciye yüklenen çalışma programı sayesinde eyleyici motorları yönlendirerek varış noktalarını gezmektedir. Ayrıca uygulanan Kalman filtresi ve güdüm algoritmasından da bahsedilmiştir. Bütünleştirilen sistemin uygulanabilirliği ve fizibilitesi test edilmiş ve sonuçlar çalışmanın sonunda verilmiştir.

\section{Design and construction of low cost sensor and GPS based autonomous unmanned ground vehicle}

\begin{abstract}
In recent years, unmanned vehicles have been quite popular for the researchers and those vehicles are still being developed by the researchers and engineers. Unmanned vehicle must do all operations without operator and must has all capabilities as controlled by the operator. In this study, tracking of waypoint by autonomous unmanned ground vehicle (UGV) has been studied. For this purpose, designed and constructed unmanned ground vehicle location is obtained by using a low cost GPS and a compass. A microcontroller is utilized as a control/decision maker. An RC vehicle chassis and motors were used as the platform. Thanks to the work program loaded on microcontroller, UGV travels the destination points by directing actuator motors. Besides, Kalman filter algorithm and a guidance system was applied to UGV. The applicability and feasibility of the integrated system has been tested and the results are given at the end of the study.
\end{abstract}

\section{GİRIŞ (INTRODUCTION)}

İlginç konularıyla insansız araçlar (İA) araştırmacılar arasında çok popüler hale gelmiştir. Buna bağlı olarak, insansız araçlar hakkında yayın sayısı oldukça fazla. Ülkemizde de artan ilgiye bağlı olarak yapılan çalışma sayısı her geçen gün artmaktadır. Teknolojideki gelişmelere bağlı olarak sivil ve askeri alanlarda insansız araçlar sıklıkla görülmeye başlanmıştır. Arama kurtarma, tarım, eğlence ve bazı ticari uygulamalarda sivil alanda kullanımı oldukça sıklaştı. Bir insansız araç kendine verilen görevleri yerine getirirken otonom, yarı otonom veya tamamen insan kontrolünde olabilir. Yarı otonom insansız araç, kendisine verilen görevi yerine getirirken insan yardımına ihtiyaç duyar. Buna karşın tam otonom araç, görevleri insan yardımına ihtiyaç duymadan yerine getirmeli. İnsansız araçlar tipine ve bulunduğu çevreye göre isimlendirilirler.

\footnotetext{
* Halit HÜLAKO, e-mail: hhulako@ firat.edu.tr

**Sadettin KAPUCU, e-mail: kapucu@gantep.edu.tr
} 
- Insansız Hava Aracı (iHA)

- Insansız Kara Aracı (iKA)

- Insansız Deniz Aracı (iDA)

- Insansız Deniz Altı Aracı (iDAA)

- Mikro İnsansız Araç (MiA)

$\mathrm{Bu}$ çalışmanın amacı bir otonom İKA tasarlayıp düşük maliyetli sensörleri ile navigasyonu sağlamaktır. Michael ve Gilbreath düşük maliyetli sensör ve mikroişlemcilerle varış noktası navigasyon sistemini dizayn etmişlerdir. Daha doğru sonuçlar almak için GPS ve sensörlerdengelen bilgiyi kaynaştırmış ve sisteme uygulamışlardır [1]. Bok - Joong Yoon ve diğerleri GPS ve elektronik pusula kullanarak bir navigasyon algoritması ileri sürmüşlerdir [2]. Yine konum doğruluğunu artırmak için çoklu GPS ve IMU (inertial measurement unit) kullanılmış ve farklı bir navigasyon metodu sunulmuştur [3]. T. Puls ve diğerleri varış noktası navigasyonunu dikey kalkış yapan bir helikoptere uygulamışlardır [4]. Daha az sensör kullanarak navigasyon sağlamak üzere Selvi ve diğerleri sadece GPS kullanarak grafiksel bir yöntemle araç navigasyonunu sağlamışlardır [5]. Bir İHA'ya düşük maliyetli sensörlerle otopilot sistemi tasarlanmış ve varış noktası takibi işlemini sağlamışlardır $[6,7]$.

\section{GÜDÜM NAVIGGASYON VE KONTROL SISTEMİ (GNK) (GUIDANCE NAVIGGATION AND CONTROL SYSTEM (GNC))}

GNK sistemi, insansız aracın, dişardan insan müdahalesi olmadan istenen hedef noktaya varması için aracı yönlendirip ve kontrolde tutmaya çalışır. GNK bu işlemleri yaparken sensörler, mikroişlemciler ve eyleyicilerden faydalanır. Hali hazırda uçaklar, gemiler, roketler ve denizaltıları bu sistemi kullanırlar [8]. GNK sistemi şekil 1'de gösterildiği gibi üç alt sistemden oluşmaktadır. Alt sistemlerin çıktıları, ilişkili olduğu alt sistemi besler [9].

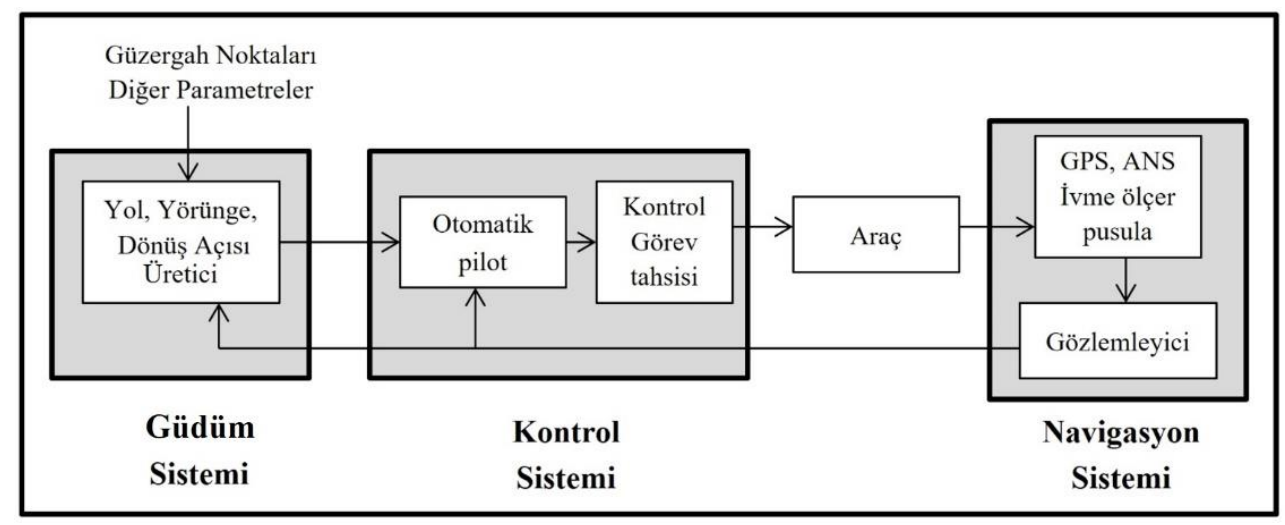

Şekil 1. GNK sistemi

Güdüm alt sisteminin görevi, aracın, istenen varış noktasına dönebilmesi için gereken dönüş açısını hesaplamaktır. Bu işlemi yaparken bir bilgisayar dönüş açısını bulabilmek için hedef noktaları ve navigasyon alt sistemini sürekli okur [10]. Güdüm alt sistemi aracın konum, hız ve ivme ile beraber izleyeceği açı, yol veya yörüngeyi de tayin etmesi gerekir [9]. Literatürde birçok güdüm algoritması bulunmaktadır. Yapılan çalışmada, bir mikrodenetleyici, İKA'nın varış noktasına yönlenmesi için gereken dönüş açısını hesaplamak, varış noktalarını ve navigasyon sensörlerini okumak için güdüm bilgisayarı olarak kullanılmıştır. Ayrıca dönüş açısını hesaplamak içinde Line of Sight (LOS) güdüm algoritması kullanılmıştır [10].

Navigasyon sistemi, aracın o anki konum, hız ve ivme bilgilerini güdüm ve kontrol sistemlerini beslemek için ölçme veya bilgi edinme olarak görülebilir. Genellikle GPS, ataletsel navigasyon sistemi (INS), IMU, yükseklik sensörü, enkoderler ve stereo vizyon kameraları navigasyon sisteminde kullanılır. Ataletsel ölçüm birimi insansız araçlarda, hava araçlarında ve roketlerde duruma ve referans eksenine göre oryantasyonu sağlar $[10,11]$. IMU sensörleri ataletsel navigasyon sisteminde de kullanılır. INS, IMU sensörlerini kullanarak referans eksenine göre alınan yolu hesaplamak için kullanır. Bu sebeple, INS, GPS' in çalışmadığı, sualtı gibi kapalı alan uygulamalarında çokça tercih edilir. Genellikle tekerlekli 
araçlarda alınan mesafeyi ölçmek ve aracın hız bilgisini tespit etmek için enkoder kullanılır. Son yıllarda bilinmeyen yerlerde kendi konumunu tespit etmek için eşzamanlı konum belirleme ve haritalama tekniği (SLAM) kullanılmaya başlanmıştır [18]. Bu teknik ile insansız araç, üç boyutlu lazer mesafe ölçer ve vizyon kameraları yardımı ile bulunduğu çevrenin haritasını çıkarıp kendi konumunu tespit eder [12].

Kontrol sistemi ise arac1, eyleyicilere verdiği komutlar ile istenen yol veya yörüngede tutmaya çalışır. Güdüm ve navigasyon sisteminin çıktıları kontrol sistemini besler. Güdüm sistemi istenen durumu üretir buna bağlı olarak, kontrol sistemi, güdüm ve navigasyon sistemlerinin farkını alarak bir eylem uygular [9]. Genel olarak kontrol sisteminde PID (proportional - integral - derivative) veya kayan kipli kontrol gibi kontrol yapıları kullanılır. Bu çalışmada eyleyiciler olarak dc ve servo motor seçilmiştir. Yön kontrolünü sağlayan servo motoru zamandan bağımsız çalıştığı için elde edilen açı değeri kontrol sekmesinde servo motora kontrol sinyali olarak girilmiştir.

\section{YAZILIM VE DONANIM (SOFTWARE AND HARDWARE)}

İnsansız kara araçları verilen görevi yerine getirebilmek için sensör ve elektronik aletler kullanır. Günümüzde çoğu mikroişlemci ve sensör uygun maliyetlerle elde edilebilmektedir. $\mathrm{Bu}$ çalışmanın amacı düşük maliyetli sensörlerle tasarlanmış bir İKA'yı belirlenen bir koordinata veya varış noktalarına bir mikrodenetleyici kullanarak göndermektir. Mikrodenetleyici içine yüklenen güdüm programıyla yönelmesi gereken açıyı hesaplayıp bu açıda kalması için eyleyicilere gereken kontrol sinyalini gönderir.

Dünya üzerinde bir yerin hassas bir şekilde konumunu belirleyebilmek için tüm dünyayı saran hayali çizgiler türetilmiştir. $\mathrm{Bu}$ çizgiler enlem ve boylamın açı değişimlerine bağlı olarak yerleştirilmiştir. İlk enlem çizgisi ekvator ile başlayıp kuzey ve güney kutbuna doğru artar. Aynı şekilde ilk boylam Greenwich ten başlayıp hem doğu hem de batıya doğru 180 derece olana kadar artar. Günümüzde enlem ve boylam değerlerini sadece bir kaç santimetre hata payı ile okumak mümkün. Düşük maliyetli GPS cihazları 2.5 metre hata payı ile bulunduğu konumu belirleyebilmektedir. Bu hata miktarı sinyallerin atmosfer tabakaları ve binalardan yansıması sebebiyledir. Bu çalışmada Mediatek GPS alıcısı kullanılmıştır. GPS alıcılarında konum bilgilerinin yanında zaman, rota, hız gibi bilgilerde alınabilmektedir. Bu veriler seri iletişim yöntemiyle NMEA (national marine electronic association) cümlecikleri şeklinde alınabilmektedir. Birçok farklı tipte NMEA cümleciği vardır. Bu mesajların bazı tipleri şekil 2' de gösterilmiştir.

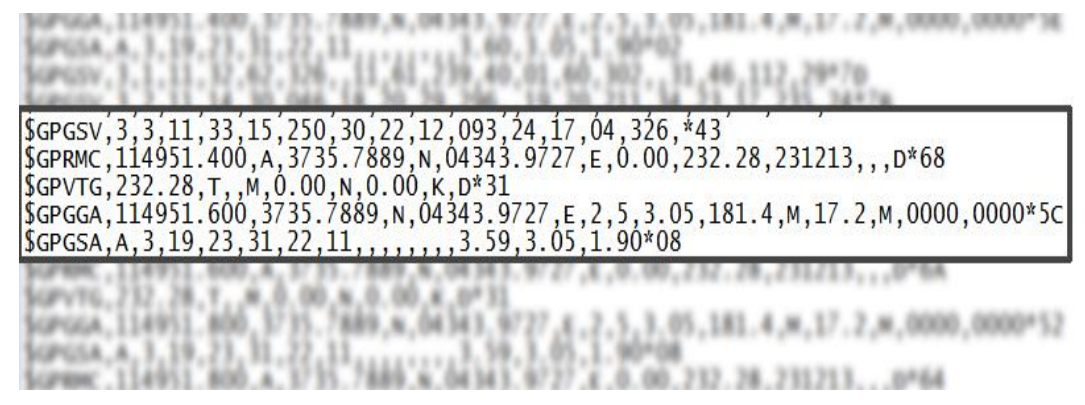

Şekil 2. Bazı NMEA cümle tipleri

Bütün NMEA cümleleri "\$" ile başlar ve " $<\mathrm{CR}><\mathrm{LF}>$ " ile mesaj sonlanır. Her tekrarlanan veri paketindeki bilgiler virgüller ile birbirlerinden ayrılmış ve ASCII (American standart code for information interchange) karakter formatındadırlar. $5 \mathrm{~Hz}$ siklıkta ve 9600 baud hizında RMC (recomended minimum sentence) tipi mesaj satırı kullanılarak ile konum bilgileri ayıklanmıştır. Gelen verilerde enlem ve boylam bilgileri derece ve dakika şeklindedir. Bu değerleri mikrodenetleyicide işleyebilmek için şekil 3’te gösterildiği gibi ondalıklı sayıya çevrilerek kullanılmıştır.

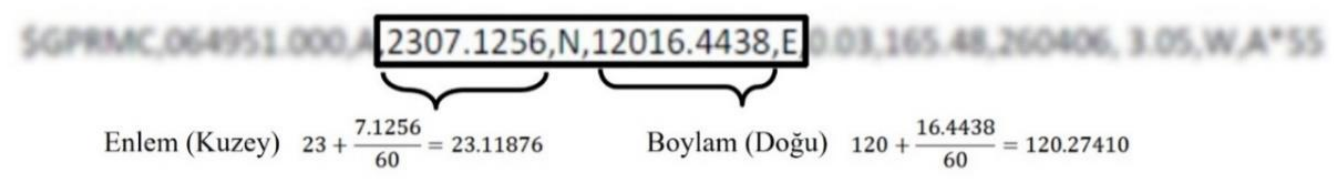

Şekil 3. NMEA cümlesinde koordinat bilgilerinin yeri ve ondalıklı sayıya dönüşümü 
Taşlı ve engebeli yerler gibi zorlu alanlarda sürüş yapabilmesi için 2 serbestlik derecesine sahip şekil 4' de gösterilen, HP crawler tipi araç şasesi ve motorları kullanılmıştır. Araç üstünde tahrik için 2 adet dc motor ve yönlendirme için ise 1 adet servo motor bulunmaktadır. Araç üstüne elektronik devreleri taşıması için bir platform yerleştirilmiştir. Elektronik pusula demir içerikli malzemelerden etkilendiği için kullanılan somun, cıvatalar ve platform alüminyum malzeme seçilmiştir. Sensör, modül ve eyleyicilerin mikrodenetleyiciye ait iletişim ve kontrol edilme yöntemleri şekil 5' te verilmiştir.

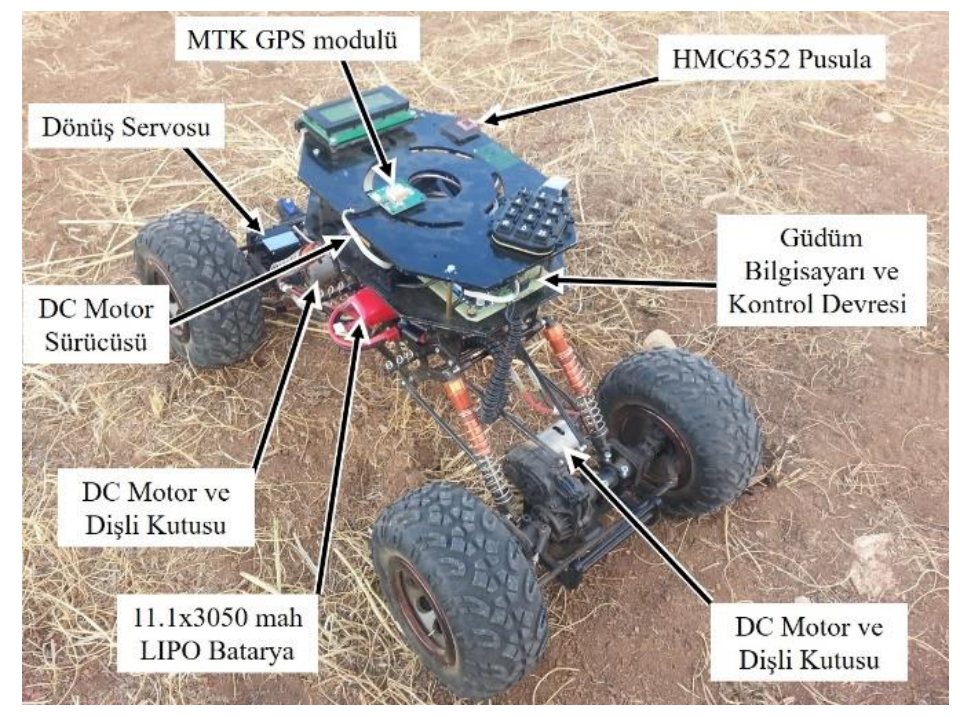

Şekil 4. Navigasyonun gerçekleştirildiği insansız kara aracı

Aracın yönelimini bulmak için Hmc 6352 elektronik pusula sensörü kullanılmıştır. Pusula 0.5 derece hassasiyete sahiptir. Sensörden yanlış sonuçlar almamak için motorlardan uzağa konulmuştur. Mikrodenetleyici ve pusula sensörü I2C (inter - integrated circuit) protokolü ile veri iletişimini sağlamaktadır. Hmc 6352 okuma ve yazma adresleri sirasiyla 43 ve 42 heksadesimal ifadeleridir. Sensörden bilgi okuyabilmek için ise ASCII karakteri A (heks 41) ifadesi sensöre yazılmalıdır. Bu basamaktan sonra $6000 \mu \mathrm{s}$ bekleme süresi program kodlarına eklenmiştir. Bu program kodları bir fonksiyona eklenmiş ve $5 \mathrm{~Hz}$ ' te okuma yapılmıştır.

Uygulamada 8 bitlik $18 \mathrm{f} 452$ mikrodenetleyici ve derleyici olarak ise CCS C kullanılmıştır. PIC18f452 32KB FLASH program hafizasina ve 256 bytes EEPROM (electronically erasable programmable read-only memory) hafizaya sahiptir. Aynı zamanda 1 adet 8 bitlik ve 3 adet 16 bitlik zamanlayıcıya sahip. Donanımsal iletişim pinlerine sahip olduğu için çoğu iletişim tipi için kolaylık sağlamaktadır. İKA' da kullanılan PIC18f452, sensör okumaları, algoritmaların işlenmesi ve motorlar için uygun sinyalin üretilmesi için kullanılmıştır. Navigasyon çalışmalarında genellikle ondalıklı sayılarla matematiksel hesaplamalar yapılmaktadır. 8 bitlik mikrodenetleyicilerde 32 bitlik ve ondalıklı sayılarla matematiksel işlemler yapmak hayli zor bir işlemdir. C tabanlı CCS derleyici 32 bitlik matematiksel hesaplamalara olanak sağlamaktadır.

GPS' ten gelen konum bilgisini alabilmek için seri iletişim kesmesi INT_RDA kullanılıp bu kesmeye öncelik verilmiştir. Bunun için PIC $18 f 452$ mikrodenetleyicisine ait donanımsal UART (universal asynchronous receiver-transmitter) pinleri kullanılmıştır. Ayrıca dijital pusula ve İKA' nın izleme esnasındaki test bilgilerini kaydetmek için kullanılan AT24C256 EEPROM çipi I2C ile iletişimi sağlamaktadır. 


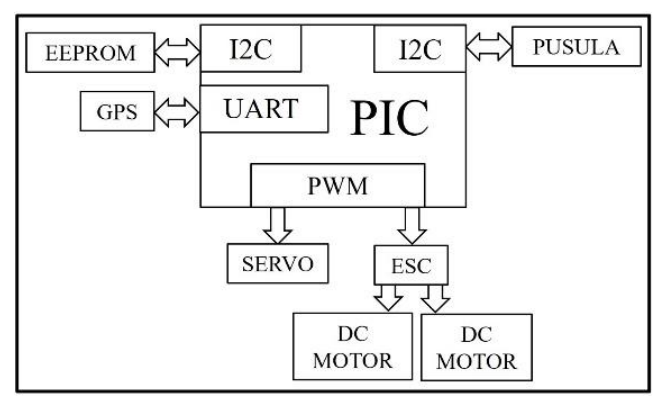

Şekil 5. İKA ya ait gömülü sistem şeması

Seçilen düşük maliyetli PIC microdenetleyicisi paralel işlem yapma kabiliyetine sahip değildir. Bu sebeple, microdenetleyici eyleyici motorları sürmek için paralel işlem yapmaya benzerlik göstererek zamanlayıcıları kullanır. Zamanlayıcılar motorlar için uygun sinyali üretir. 16 bitlik Timer1 zamanlayıcısı, 20 Mhz kristal ve "ps" değerinin 4 seçilmesiyle PWM (pulse - width modulation) sinyali oluşturulmuştur. Zamanlayıcılar genellikle motor sürücüleri için gerekli sinyali üretmeye çalışırken mikrodenetleyicinin işlem süresinin çoğunu tüketmektedir. Bu sebeple sensörler, seri iletişim okuması ve güdüm algoritmasını icra etmek için yeterli süre kalmamakta ve serri iletişimile gelen bilgiyi kaçırma durumuyla karşı karşıya kalmaktadır. Bu sorun aşağıda belirtilen yöntemle aşılmıştır. Timerl zamanlayıcı kesmesi ile oluşturulan $50 \mathrm{~Hz}$ ' lik servo ve de motor kontrol sinyali şekil 6'da belirtildiği gibi 3 bölümden oluşmaktadır [13]. Çoğu uygun maliyetli servo motor $50 \mathrm{~Hz}$ ' de, 1 milisaniye ile 2 milisaniye arasında değişen sinyal aralığında kontrol edilmektedir.

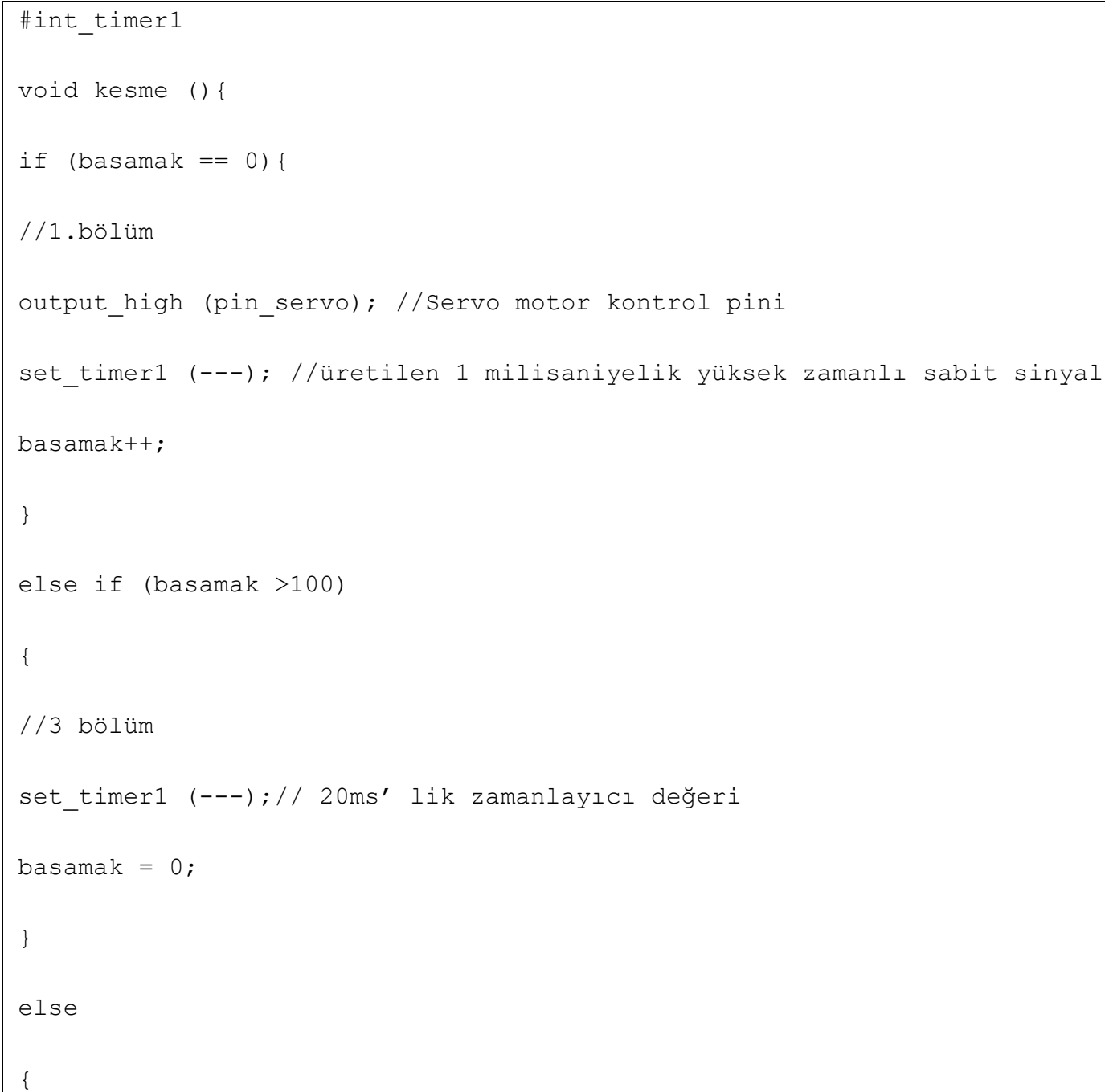



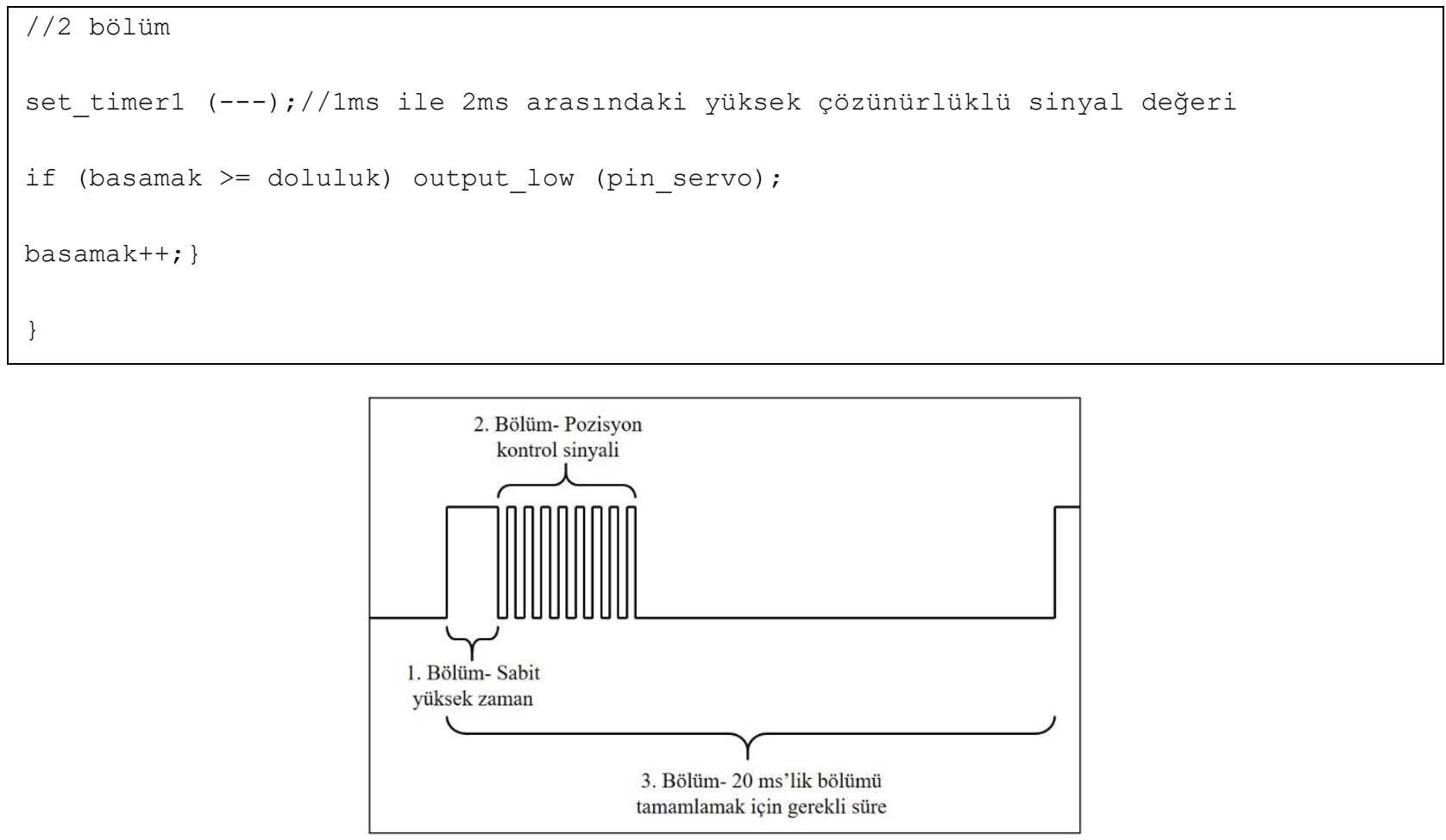

Şekil 6. Eyleyici motorları sürmek için gerekli olan çözüm yöntemi

Tahrik motorlarına ait elektronik hız kontrol ünitesi ve direksiyon servo motoru 1 ve 2 milisaniye arasında değişen elektrik sinyalleriyle kontrol edilmektedir. Yön kontrol servosu 1.5 ms' de yönlendirme olmadan İKA' nın dönüş açısını ortalamaktadır. Elektronik hız control ünitesi 1.5 ms' de tahrik motorlarını durdurmaktadır. Şekil 6'da 1. bölüm sabit olan 1 milisaniyelik yüksek zamanlı sinyali belirtmektedir. 2. bölümde ise servo ve elektronik hız kontrol ünitesi (ESC) için kontrol sinyali üretmektedir. 3. bölüm ise $50 \mathrm{~Hz}, 20 \mathrm{~ms}$ olan sinyali tamamlamak için gerekli olan alçak sinyali oluşturmaktadır. İKA' nın genel çalışma prensibi ise şekil 7' de belirtilmiş̧tir [13].

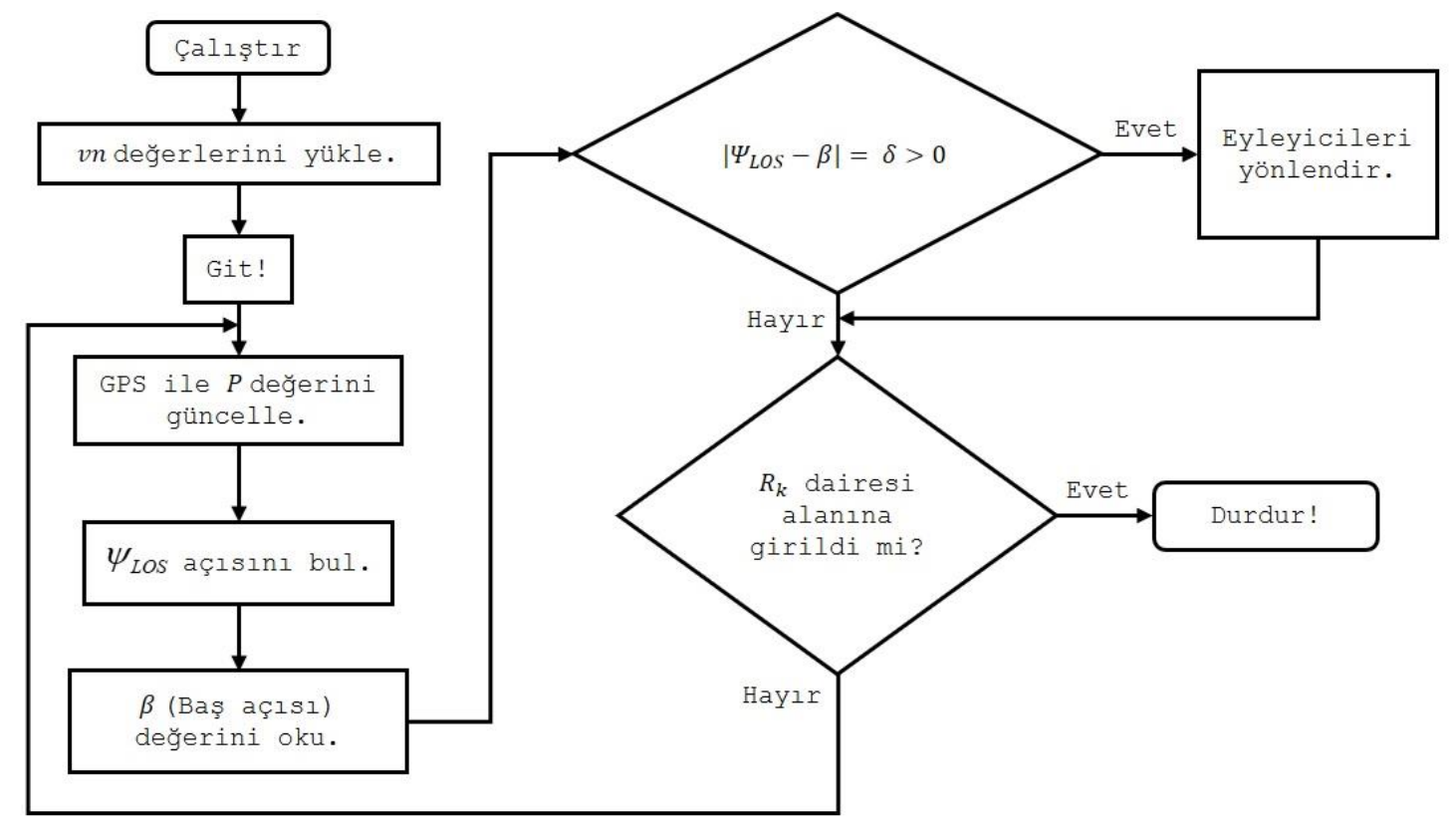

Şekil 7. İKA çalışma algoritması 


\section{GÜDÜM SİSTEMİ (GUIDANCE SYSTEM)}

Bir güdüm sistemi, insansız kara aracını belirlenen bir noktaya ulaştırmak veya yönlendirmek için, birçok farklı yola yapılabilir. Güdüm sistemi hava ve yol durumuna, engel veya çarpışma durumlarına bağlı olarak en uygun açı değeri, yol veya yörüngeyi üretmeli. Pure Pursuit (PP) ve Line Of Sight güdüm algoritması sıklıkla kullanılan algoritmalar arasındadır $[10,9]$. Güdüm sistemi IKA aracının anlık konum bilgilerini almak için GPS' i kullanır. (1) nolu ifadede görüldüğü üzere varış noktaları, geçiş güzergahını tanımlayan enlem ve boylam kümesidir. Şekil 7' de gösterildiği gibi, İKA bulunduğu noktayı ve istenen noktanın enlem ve boylam değerlerini karşılaştırır. Varış noktasına ulaşıldığı zaman güdüm sistemi sonraki noktaya yönlenir. $R_{k}$ varış noktası dairesinin yarıçapını belirtir. İKA bu hedef noktasının sınırlarından veya daire alanına girdiği zaman IKKA sonraki varış noktasına yönlenip odaklanır. Her varış noktası için tanımlanan bu daire alanı IKKA' nın kendi alanına girip girmediğini algılar [9, 14]. Bu bir mesafe değeridir. Varış noktalarının daha detaylı olmasına bağlı olarak zaman, hız ve İHA' lar için yükseklik ifadeleri de içerebilir.

$$
v n=\left\{\left(\text { enl }_{0}, \text { boyl }_{0}\right),\left(\text { enl }_{1}, \text { boyl }_{1}\right), \ldots\left(\text { enl }_{n}, \text { boyl }_{n}\right)\right\}
$$

LOS güdüm algoritmasının hedefi LOS konumu ve İKA' nın o anki konumu arasındaki mesafe farkını azaltmaktır. Böylece güdüm aracı istenen konuma taşıyacaktır. Burada LOS konumu varış noktasından farklıdır. LOS konumu 2 varış noktası arasındaki çizgi üzerindeki bir noktadır. LOS böylece rotadan kaçma hatasını azaltmaya çalışır. Rotadan kaçma hatası İKA' nın bulunduğu konum ile yol, yörünge veya 2 varış noktası arasındaki çizgi üzerinde noktalardır. Bu çalışmada PIC18f452 mikrodenetleyiciye en temel şekilde LOS güdüm algoritması yüklenmiştir. Burada $\psi_{L O S}$ ve $P_{k}$ sırasıyla yönelme veya LOS açıSı ve o anki varış noktasını ifade etmektedir. $P_{L O S}$ ve $P$ ise LOS konumunu ve o anki konumu ifade etmektedir. Burada $P_{L O S}$ o anki varış noktası olan $P_{k}$, yı göstermektedir. Buda İKA' nın $P_{k}$ ve $P_{k-1}$ arasındaki yola veya çizgiye bağlı kalmaksızın $P_{k}$,ya odaklanacağını göstermektedir. Koordinat sisteminde kuzey ekseni dönmesi gereken dönüş referans eksen olarak tanımlanmıştır. $\delta$ açısı sonuçta İKA' nın miktarıdır. Böylece LOS açısı ve yönlendirme açısı kuzey

eksenine bağlı olarak karşılaştırılır. $\psi_{L O S}$ açısı arctanjant ile elde edildiğinde sürekli bir harita edilememektedir. Bu sebeple oluşturulan koordinat sisteminde 4 bölge için, IKA hangi bölgede ise o bölge için ayrı bir hesaplama yapılmaktadır. Dört bölge için program kodları şekil 8-12. grafiklerde belirtilmiştir. 


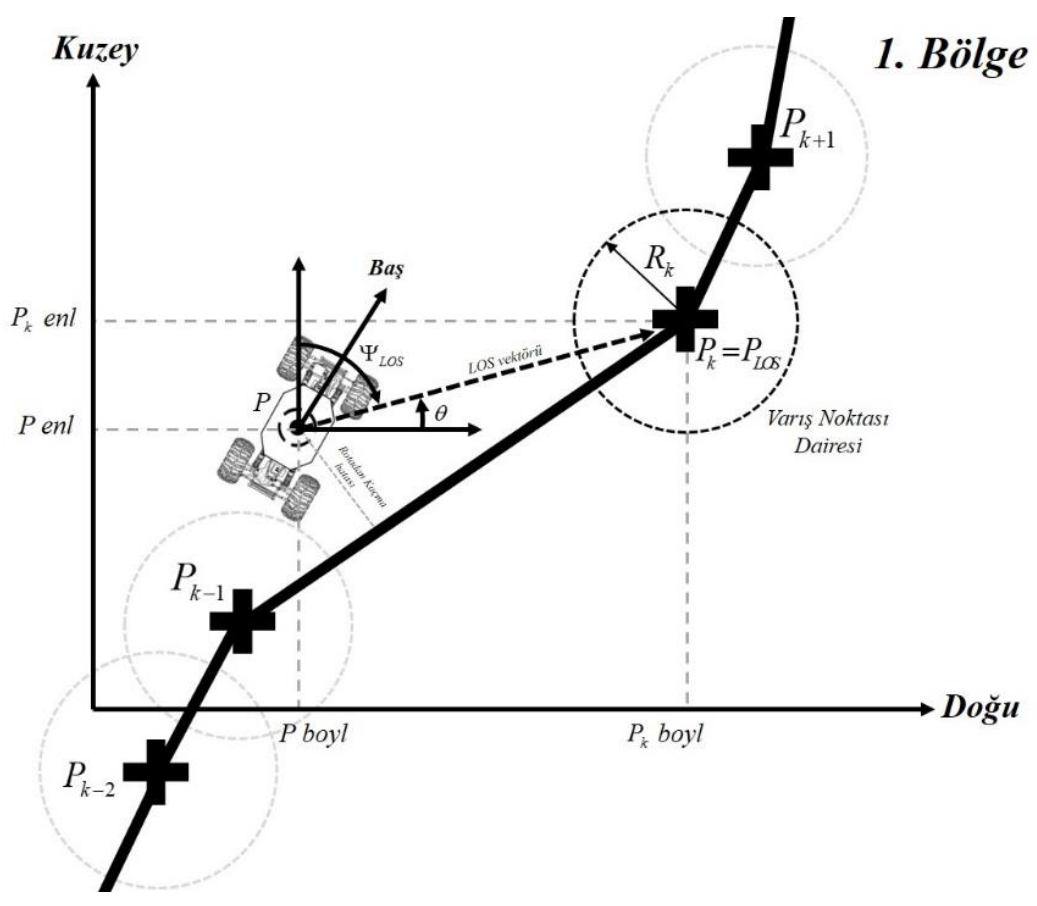

Şekil 8. Birinci bölge için LOS açısının gösterimi

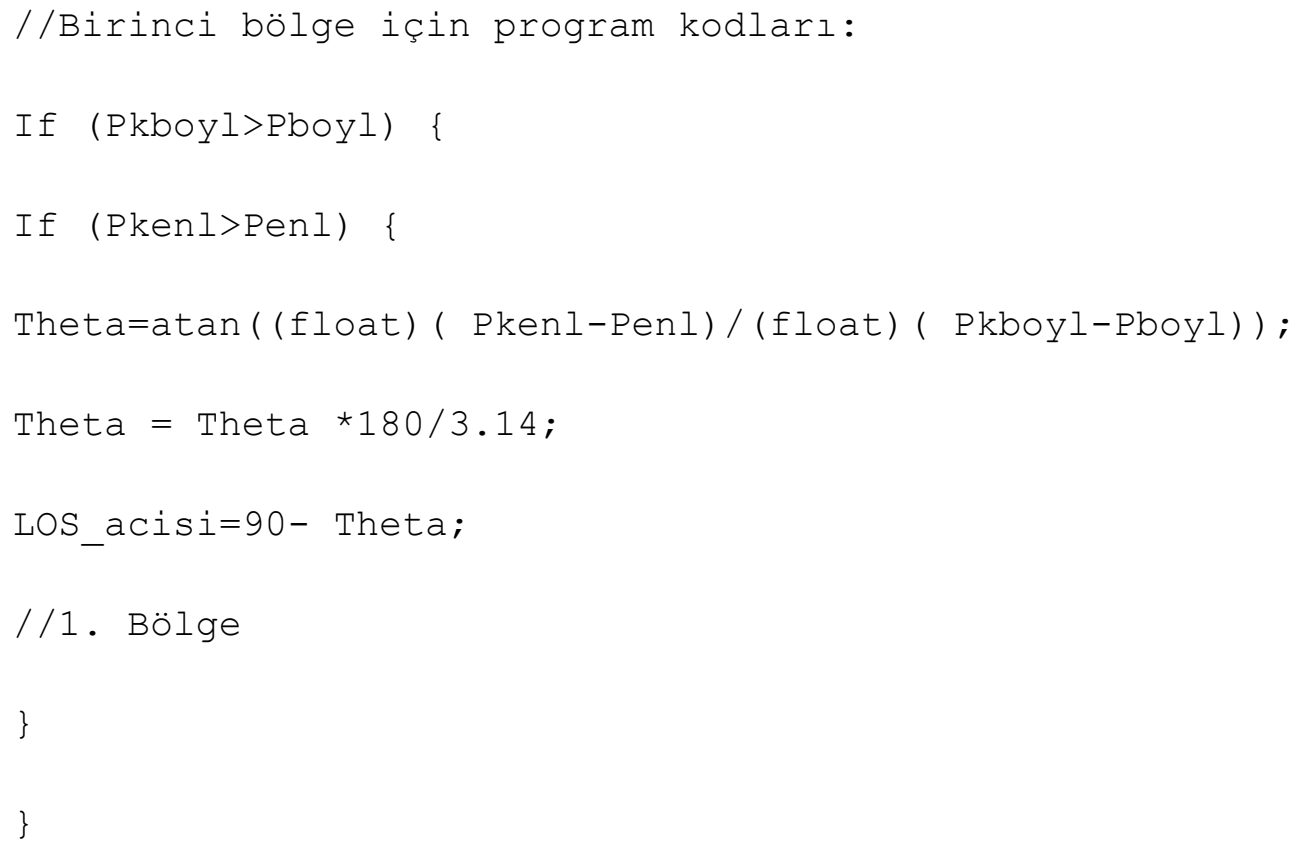




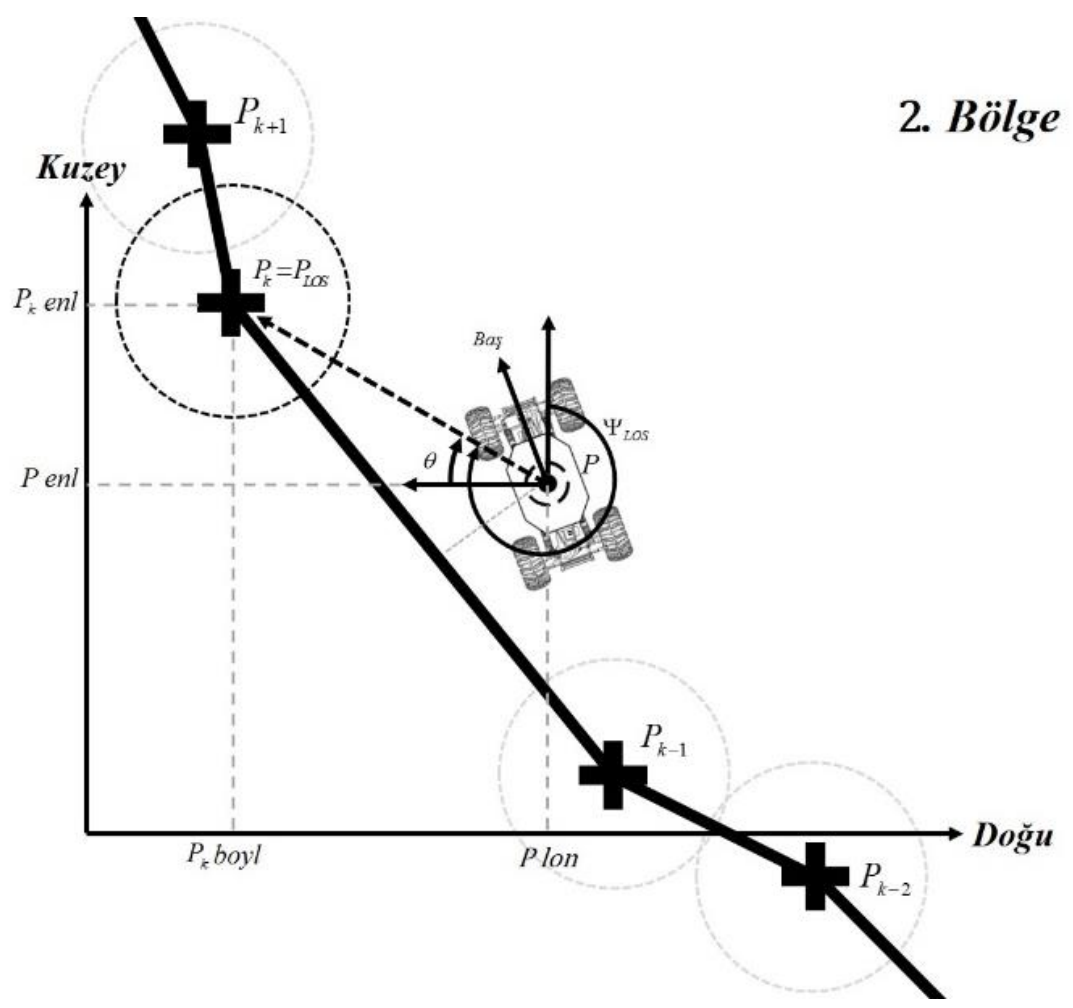

Şekil 9. İkinci bölge için LOS açısının gösterimi

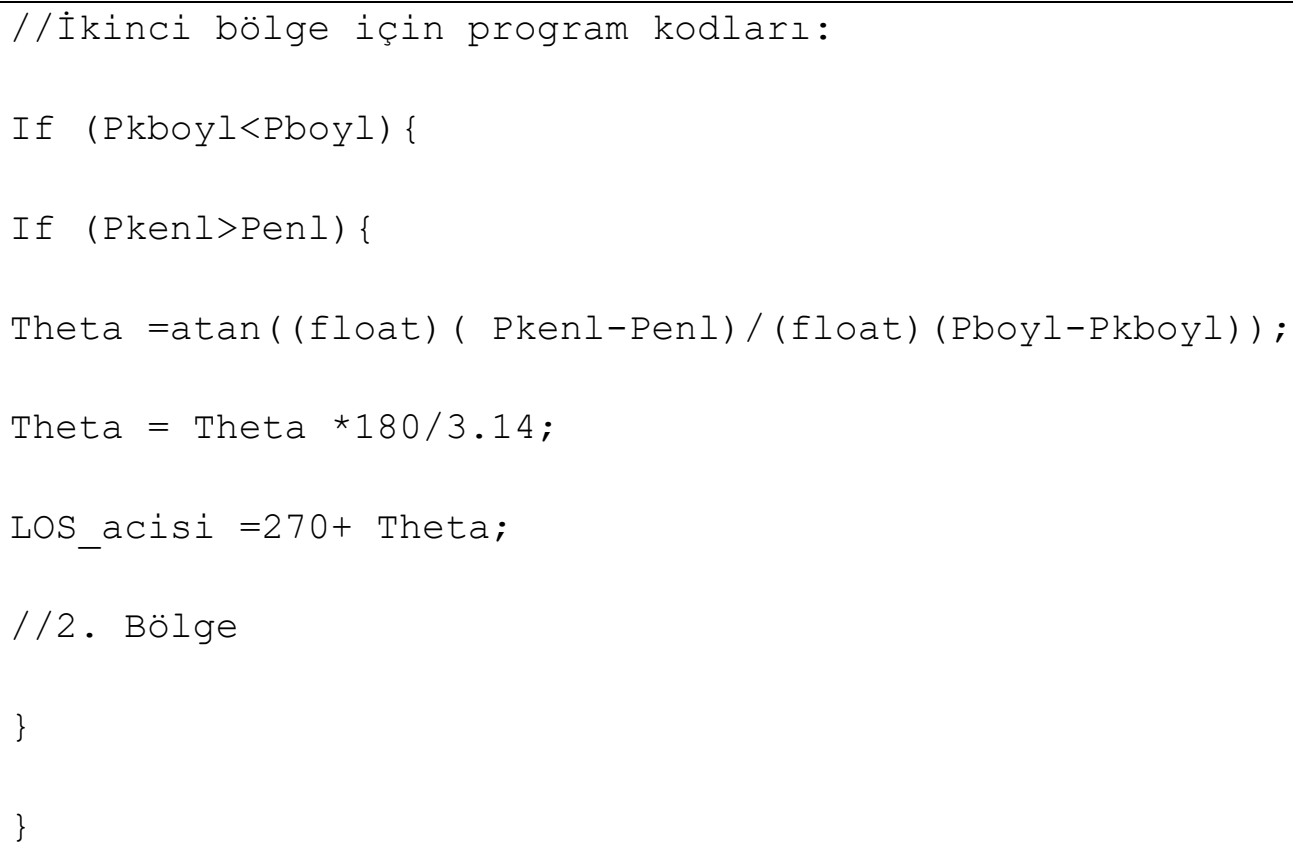




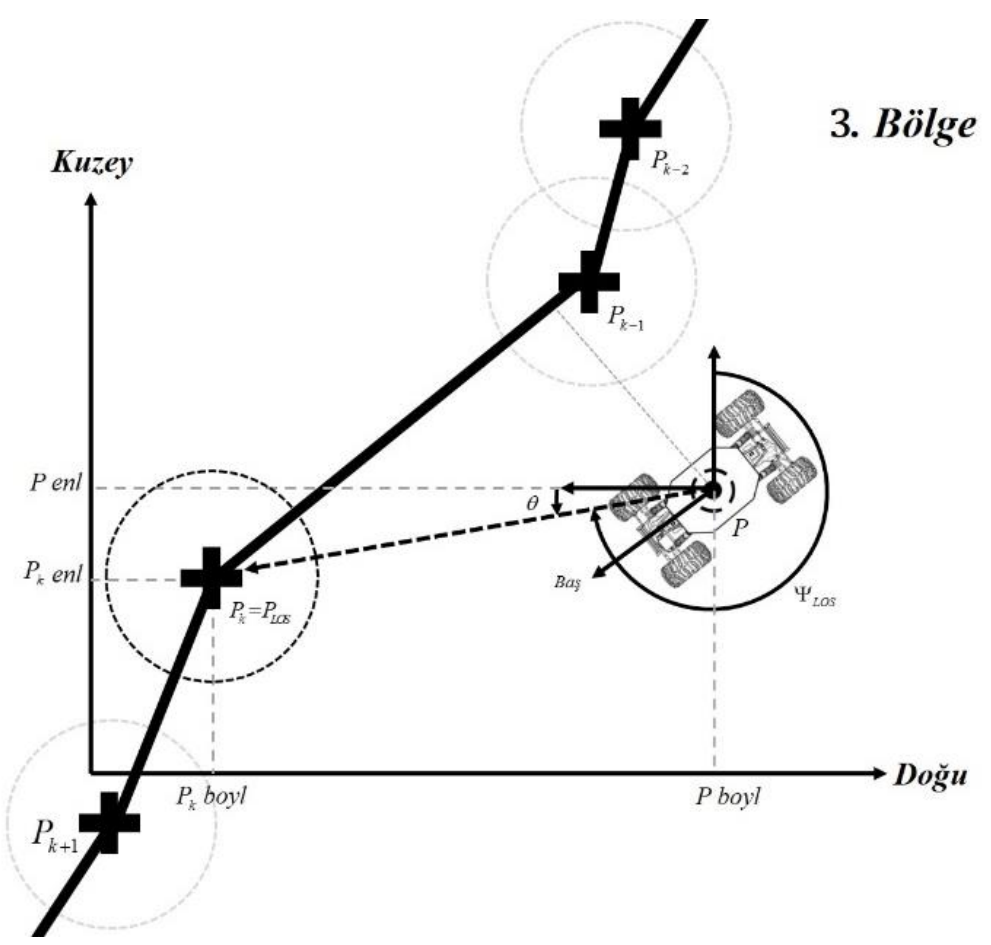

Şekil 10. Üçüncü bölge için LOS açısının gösterimi

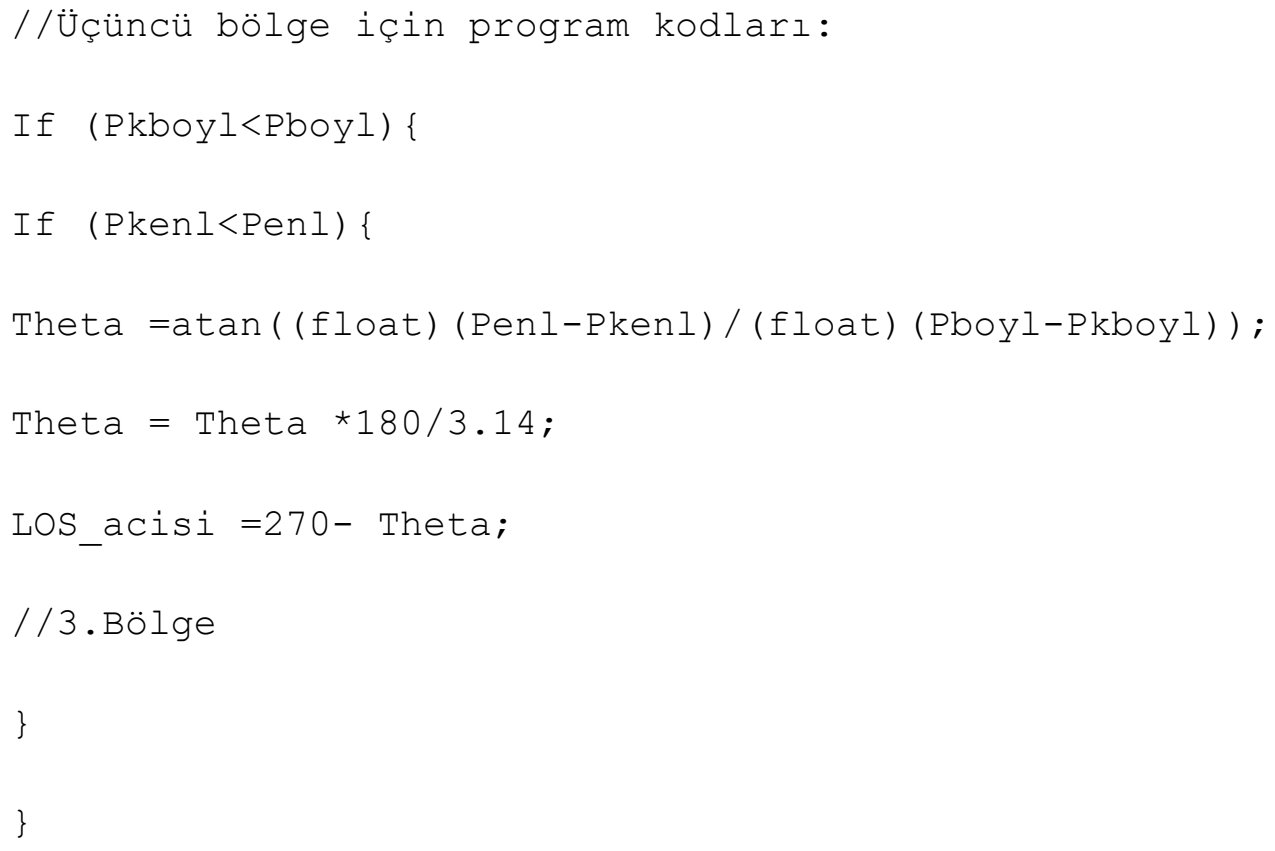




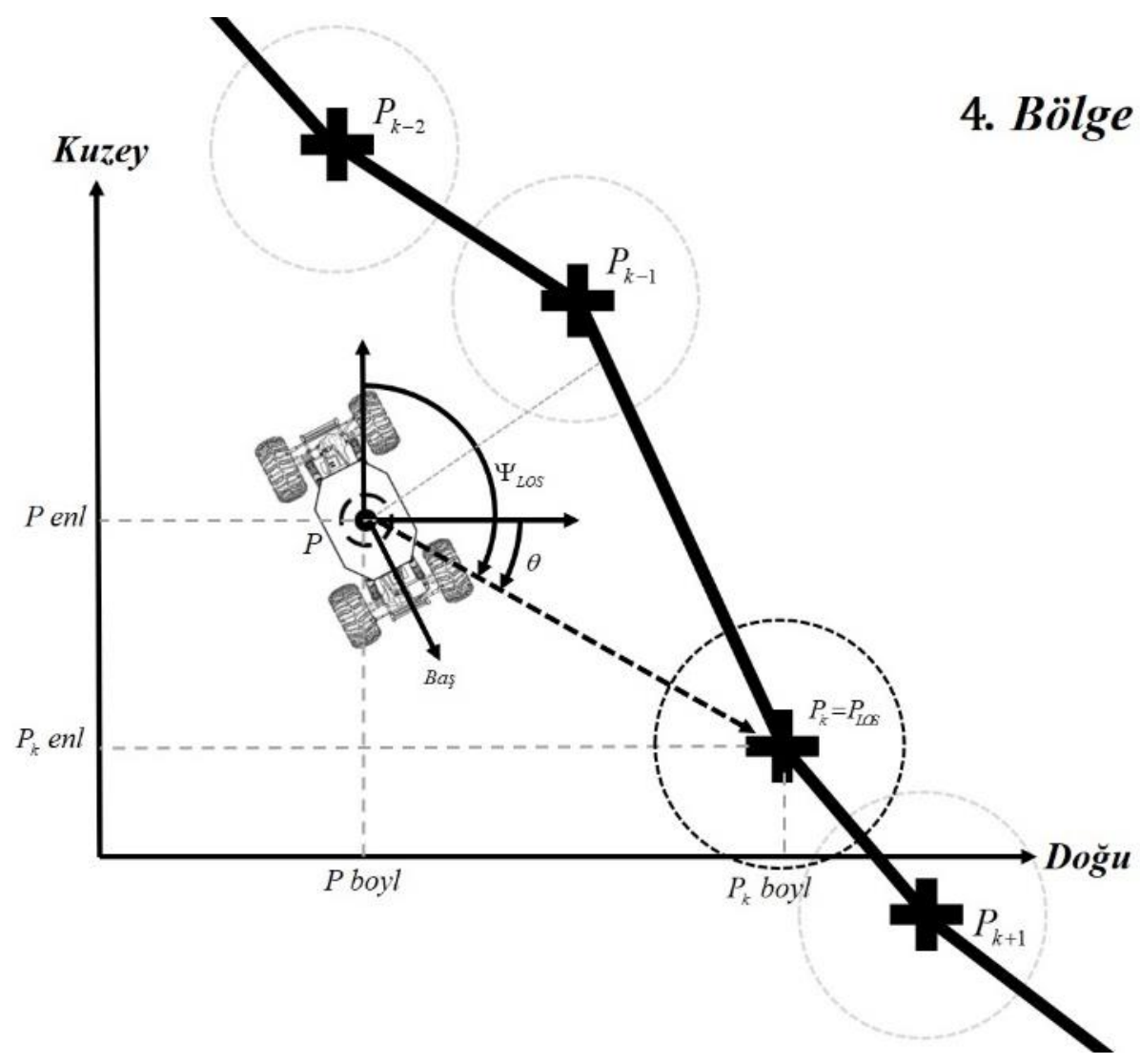

Şekil 11. Dörtüncü bölge için LOS açısının gösterimi

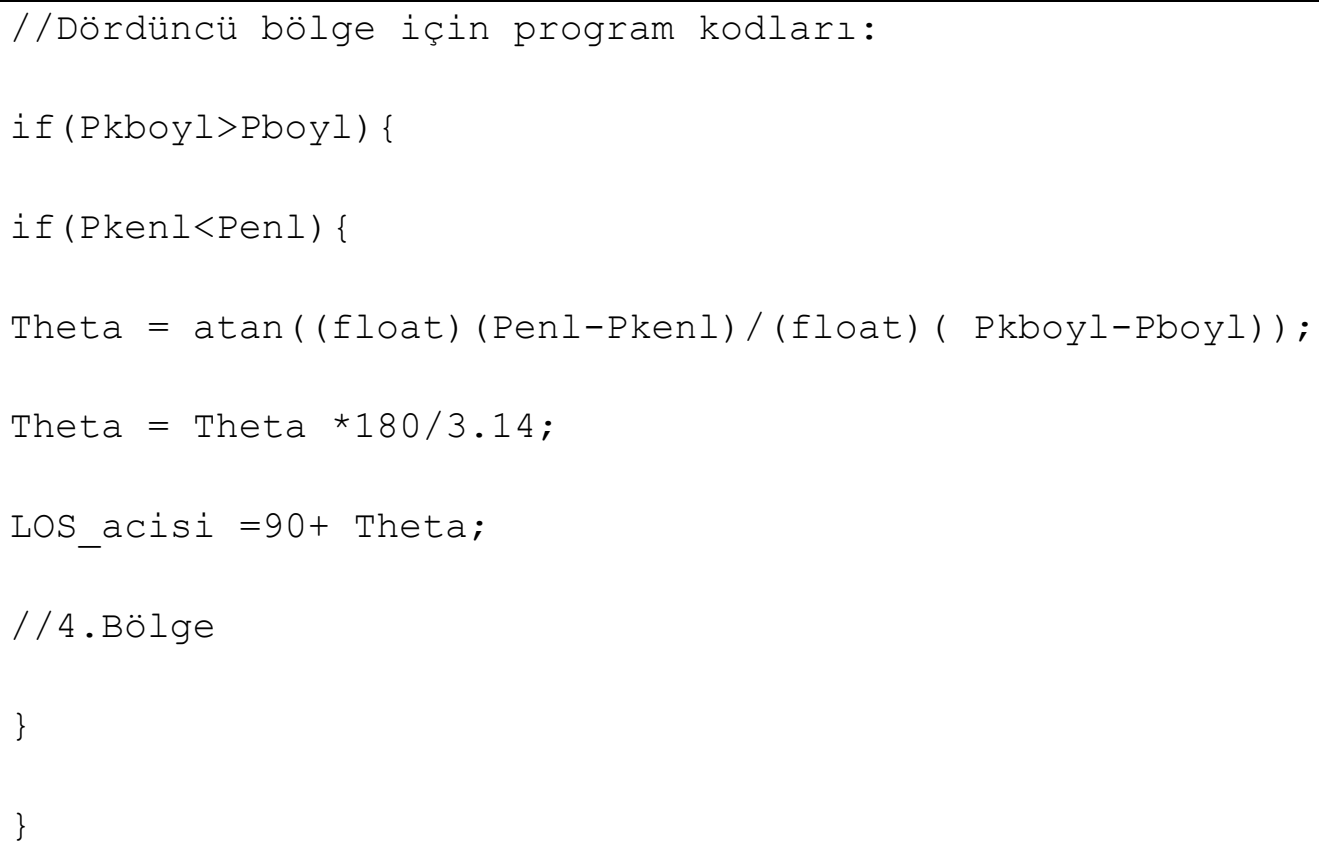




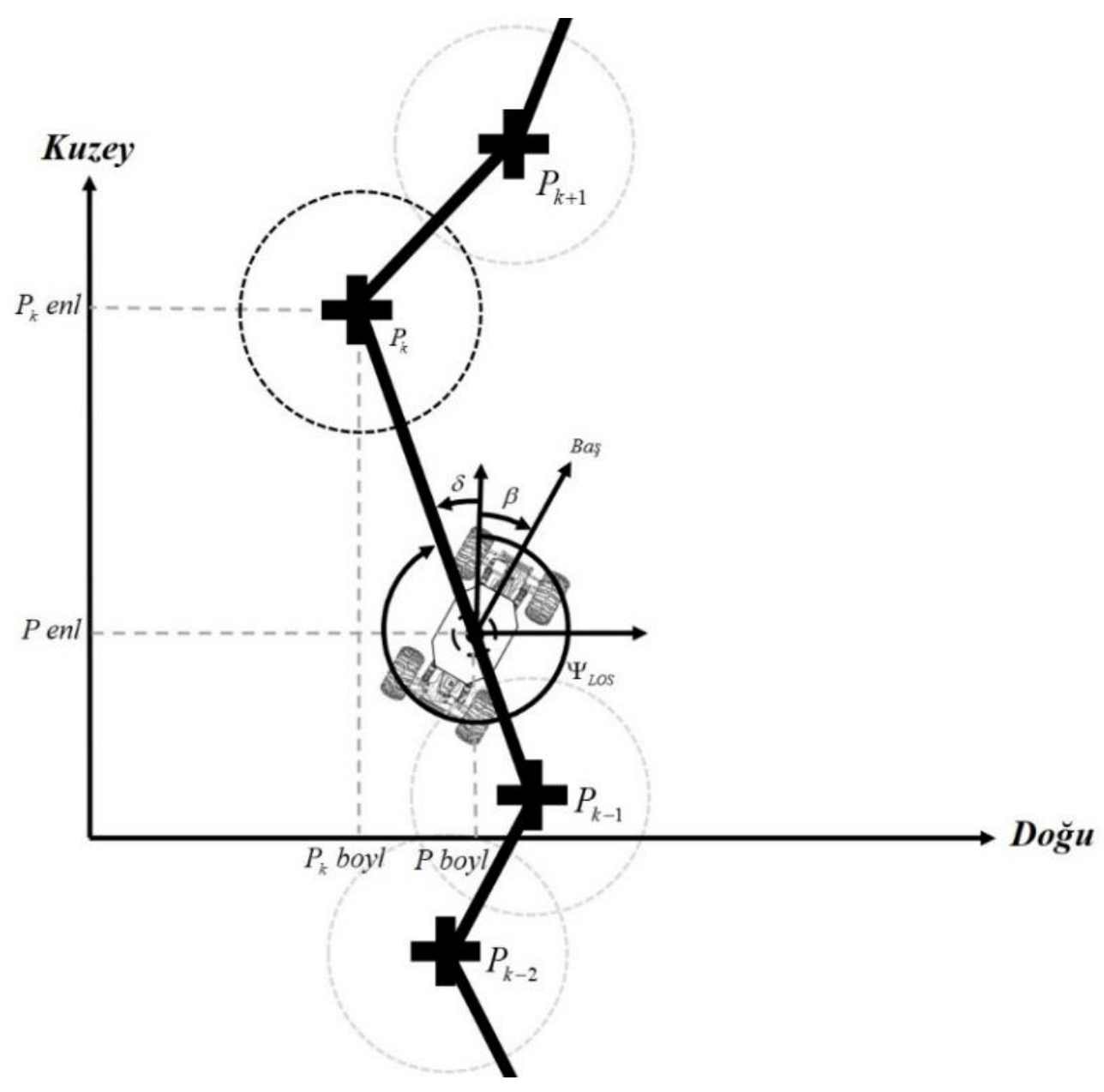

Şekil 12. Dönüş açısının gösterimi

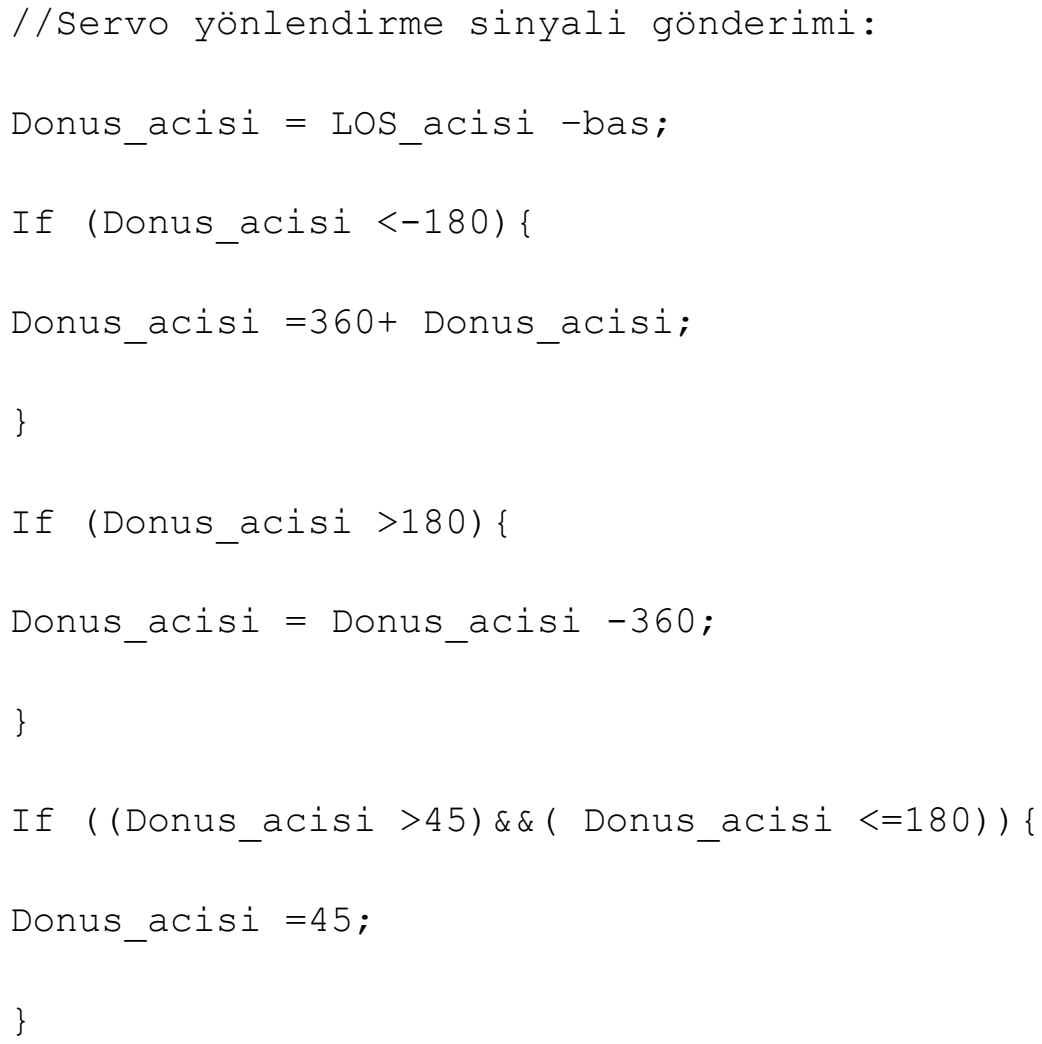




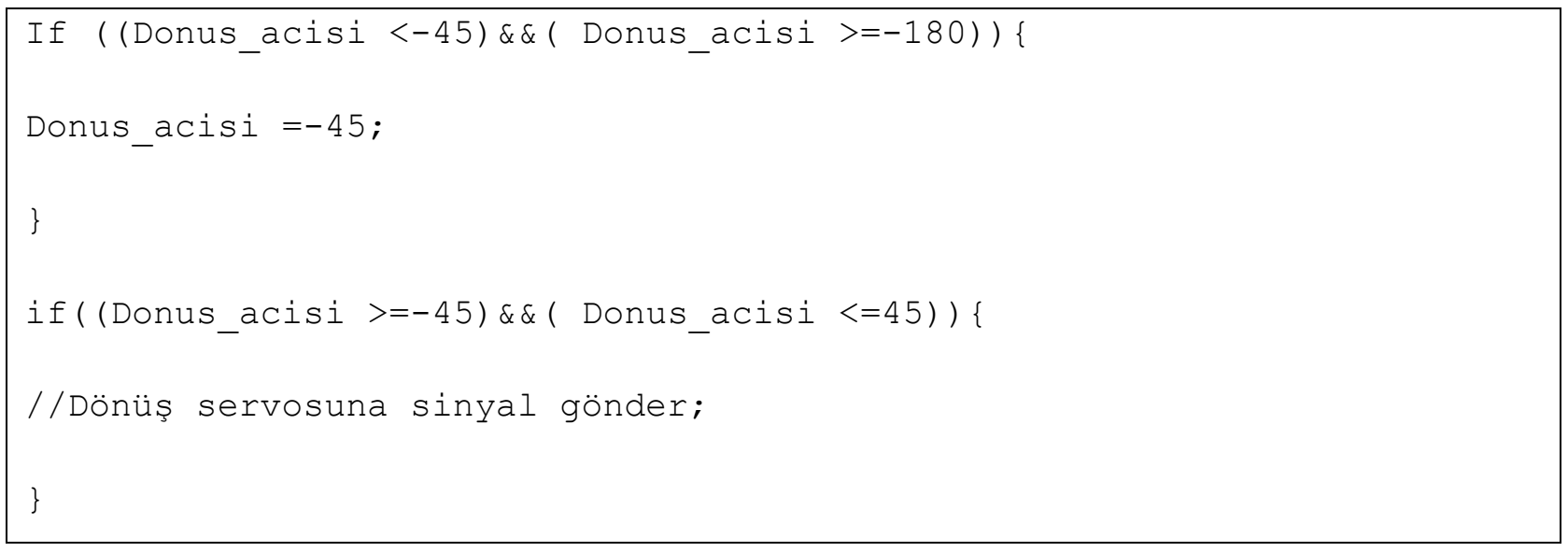

IKKA üzerinde yönelmeyi sağlayan servo motoru varış noktasına yönlenirken dönüş miktarı +45 ve -45 derece arasında sınırlandırılmıştır. Dönüş açısı miktarı, LOS açısı ve İKA aracının baş açısının farkından elde edilmektedir. İKA araçları çalışma ortamı sebebiyle diğer insansız araçlardan daha fazla titreşimlere mazur kalmaktadır. Bu sebeple elde edilen dönüş açısına bağlı olarak dönüş yapan servo motor yüksek frekanslı sinyallere cevap vermekte, buda istenmeyen durumlara sebep olmaktadır. Elde edilen dönüş açısını gürültülerden arındırmak için Kalman filtresi kullanılmıştır.

\section{KALMAN FÍLTRESI (KALMAN FILTER)}

Kalman Filtresi havacılık ve uzay alanlarında sıklıkla kullanılan yöntemlerden biridir. Ayrıca, doğrulayıcı ve tahmin edici kabiliyeti sayesinde dijital sinyal filtrelerinden en çok tercih edilen yöntemde denilebilir. Birden fazla sensörün çıktılarının kaynaştııılıp daha doğru sonuçlar elde etmek amacıyla da kullanılır. Kalman filtresi, giriş ve çıkış bilgilerini ve geçmiş verileri de kullanarak dinamik sistemin durumunu tahmin etmeye çalışır [15]. Hatalar, çevresel etkiler ve titreşimler gibi anlık hesaplamalarda İKA'nın baş açısını etkileyecektir. Böylece, değişimler geçici olsa bile İKA, her ayrık zaman diliminde dönüş servosu açısını değiştirecektir. Daha düzgün ve gürültülerden temizlenmiş bilgi alabilmek için bir filtre algoritması dönüş açısına uygulanmıştır. Birçok farklı filtre algoritması bulunmaktadır. Fakat, Kalman filtresi tahmin edici ve doğrulayıcı tipi sayesinde navigasyon uygulamalarında genellikle tercih edilmektedir [16]. Başlangıçta Kalman filtresine göre ayrık zaman aralıkları için bir model formüle edilir.

$x_{k}=A x_{k-1}+B u_{k-1}+w_{k-1}$

$z_{k}=H x_{k}+v_{k}$

Burada $x_{k}$ durum tahminidir. $Z_{k}$ ise ölçülen ham değer aynı zamanda filtrelenmek istenen değerdir. $u_{k}, v_{k}, w_{k}$ değişkenleri sırasıyla kontrol girişi, ölçüm ve proses gürültüleridir. $k-1$ önceki okumayı ve $k$ ise şuan ki durumu göstermektedir. $A, B, H$ matrixleri ise sabit olarak alınmıştır [17,16]. Oluşturulan 1. grub denklemler $(4,5)$ ise zaman güncelleme denklemleridir. $\hat{x}_{k}^{-}, Q$ ve $P_{k}^{-}$sirasiyla ön durum tahmini, proses gürültü kovariyansı ve hata kovariyansıdır. $Q$ matrixi ise bu çalışmada sabit olarak alınmıştır. 2 . grup denklemler $(6,7,8)$ ise ölçüm güncelleme denklemleridir. $K_{k}$ kalman kazanc1, $\hat{x}_{k}$ sonraki durum tahmini ve $\hat{x}_{k}^{-}$ise önceki durum tahminidir. Sonuç olarak zaman güncelleme denklemlerini beslemek için sonraki hata kovariyansı $P_{k}$ bulunur.

$\hat{x}_{k}^{-}=A \hat{x}_{k-1}^{-}+B u_{k-1}$

$P_{k}^{-}=A P_{k-1}^{-} A^{T}+Q$

$K_{k}=P_{k}^{-} H^{T}\left(H P_{k}^{-} H^{T}+R\right)^{-1}$

$\hat{x}_{k}=\hat{x}_{k}^{-}+K_{k}\left(z_{k}-H \hat{x}_{k}^{-}\right)$

$P_{k}=\left(I-K_{k} H\right) P_{k}^{-}$ 
Zaman güncelleme bölümü sistemi ileri taşır. Ölçüm güncellemesi ise zaman güncelleme bölümünü besler. $\mathrm{Bu}$ döngü her ayrık zaman diliminde gerçekleşir [16]. Döngünün başlaması için $\hat{x}_{k-1}^{-}$ ve $P_{k-1}^{-}$değerleri verilmeli. $\hat{x}_{k-1}^{-}$değerinin yakın tahmini, gerçek sonuca daha çabuk ulaşmasını sağlar.

\section{TESTLER (TESTS)}

Düşük maliyetle yapımı gerçekleştirilen İKA' nın varış noktası takibi gerçekleştirilmiştir. Yapılan testler, şekil 13' te gösterildiği gibi engelsiz düz olan geniş bir arazide gerçekleştirilmiştir. Tasarlanan İKA'nın varış noktası takip testleri, 3 adet varış noktası ve çoklu varış noktası için yapılmış ve sonuçları sunulmuştur. İKA programı varış noktası takip döngüsüne girmeden önce izlenmesi gereken hedef noktalar yüklenmiştir. $\mathrm{Bu}$ aşamadan sonra bir döngü varış noktalarına varılana kadar çalışır. Mikrodenetleyici her 200 ms'de bir konum ve açı bilgilerini harici EEPROM'a yüklemiştir. Varış notası şemaları ve elde edilen sonuçlar aşağıdaki grafiklerde gösterilmiştir.

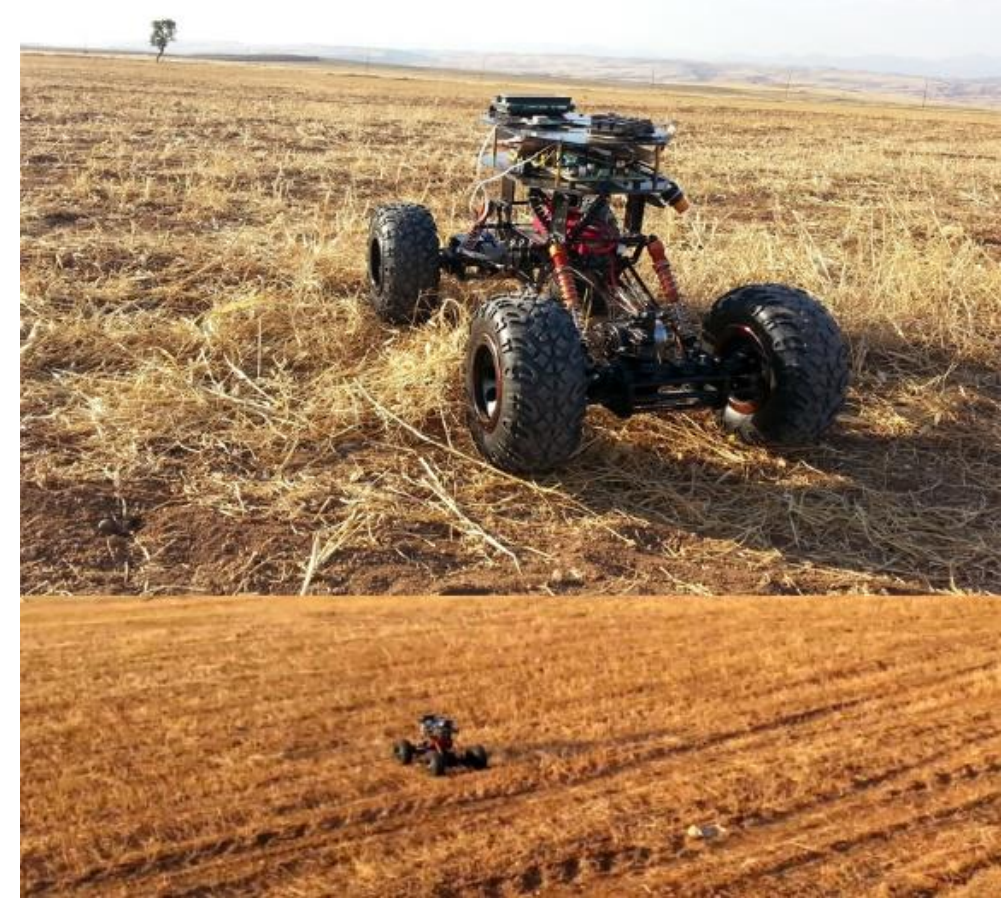

Şekil 13. Testlerin gerçekleştirildiği uygulama alanı.

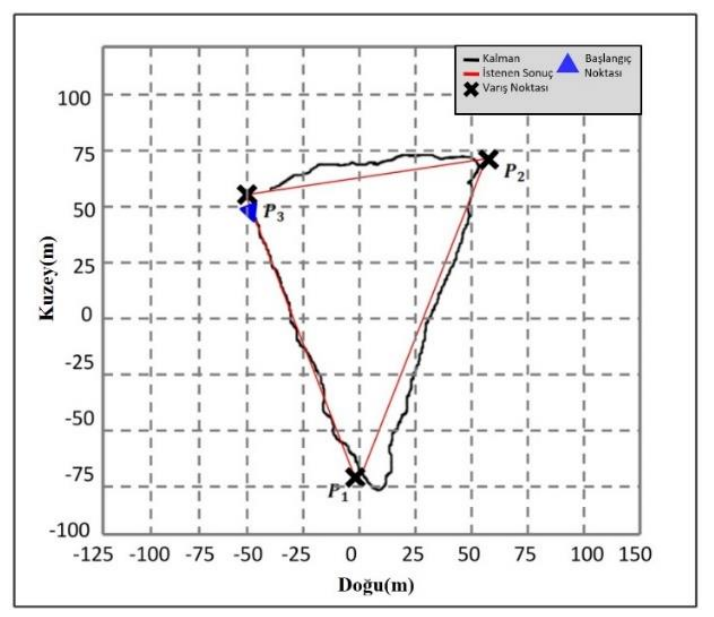

Şekil 14. İKA'nın 3 farklı varış noktası için izleme sonuçları 


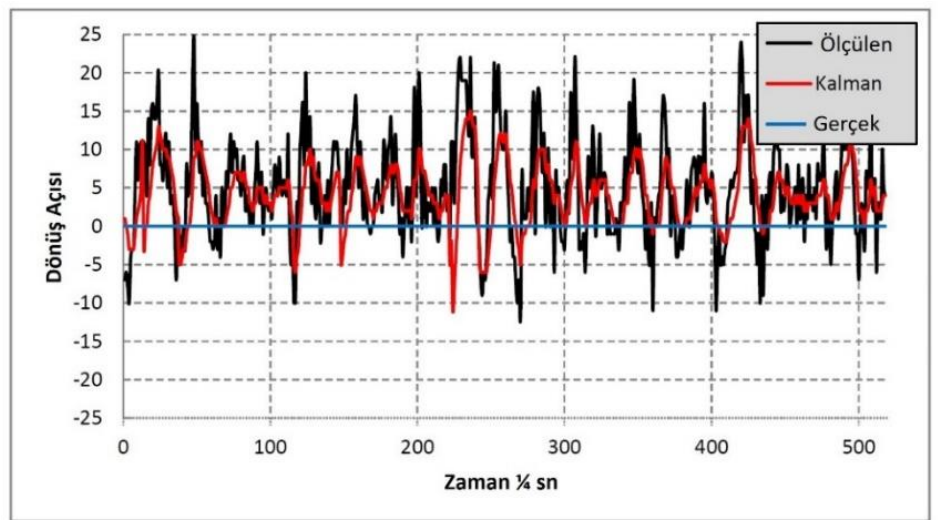

Şekil 15. Varış noktası takibi esnasında başlangıç noktası ve birinci varış noktası arasındaki dönüş açısı değerleri

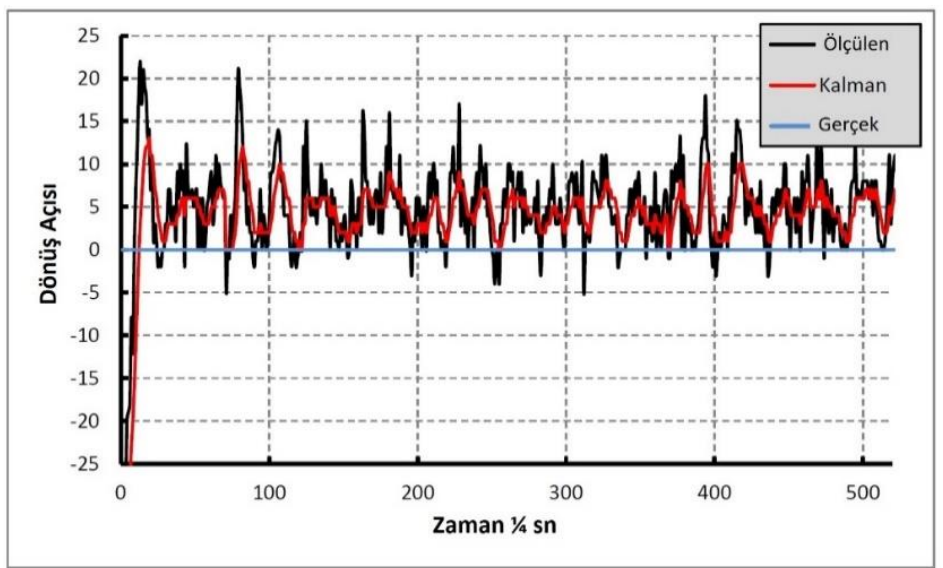

Şekil 16. Varış noktası takibi esnasında birinci ve ikinci varış noktası arasındaki dönüş açısı değerleri

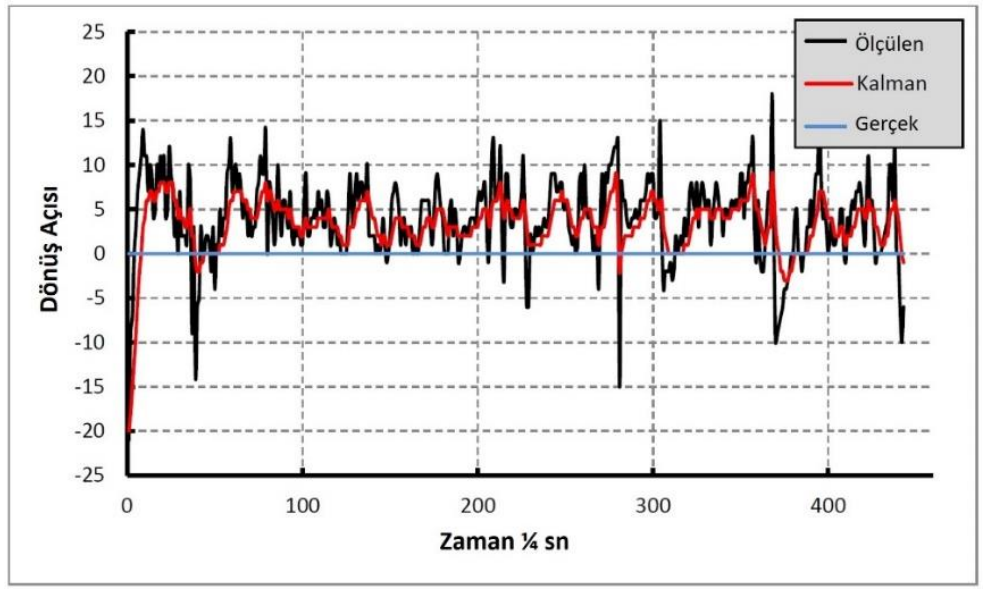

Şekil 17. Varış noktası takibi esnasında ikinci ve üçüncü varış noktası arasındaki dönüş açısı değerleri Çoklu varış noktası için test sonuçları: 


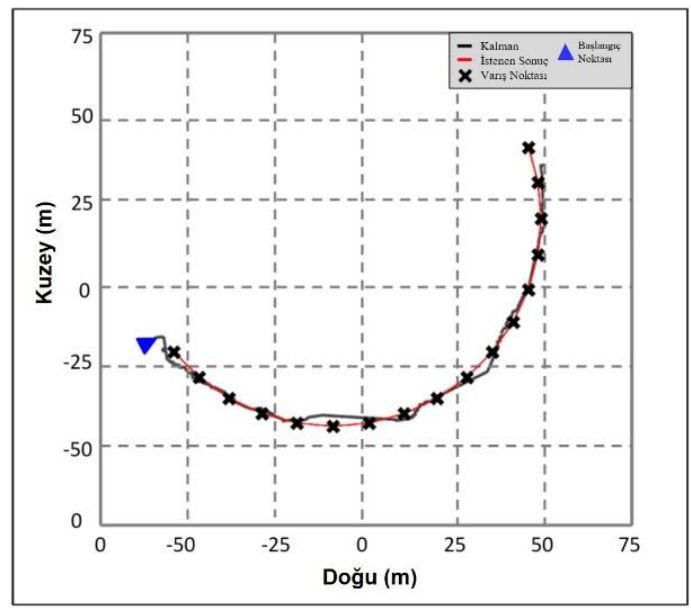

Şekil 18. İKA'nın çoklu varış noktası için izleme sonuçları

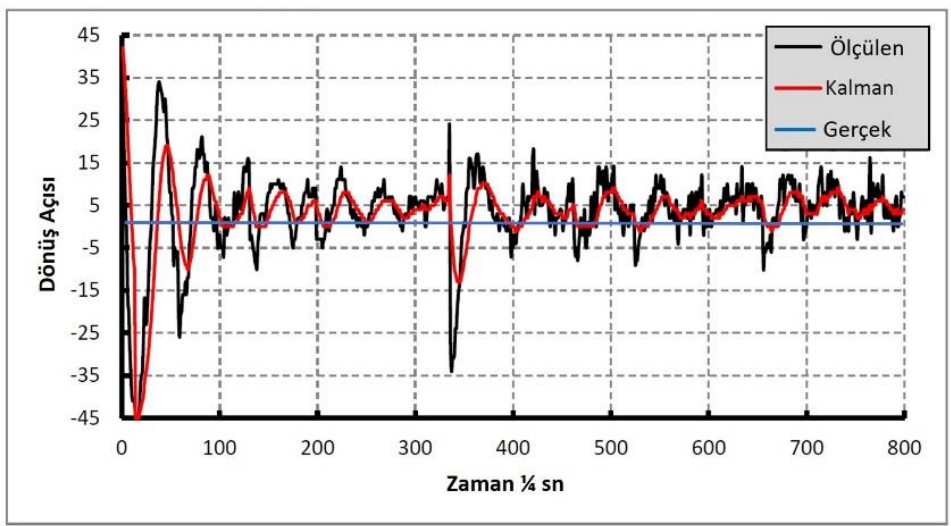

Şekil 19. Çoklu varış noktasına ait dönüş açısı değerleri

Şekil 14 ve $18^{\prime}$ te belirtilen grafiksel sonuçlardaki esas hata GPS' ten alınan düşük hassasiyetteki konum bilgisinden kaynaklanmaktadır. $P_{k}$ değeri $P_{L O S}$ değerine eşit seçildiği için rotadan kaçma hatası küçülmemektedir. Aracın yörünge veya yol üzerinde daha az hata ile devam edebilmesi için 2 komşu varış noktası arasında $P_{L O S}$ değerleri seçilmelidir böylece rotadan kaçma hatası değeri azalacaktır. Bunun yanında çalışmada büyük çaplı değerlerdeki varış noktası dairesi daha büyük rotadan kaçma hatasına sebep olmaktadır. Şekil 15,16,17 ve 19' da gösterilen grafiklerde ölçülen değerler Kalman filtresiyle filtrelenmiştir. Böylece, yönlendirme motoruna daha az gürültülü sonuçlar girdi olarak girmektedir. Buda motorun, istenen açı etrafinda daha az salınım yapmasına sebep olmuştur. Çoğunlukla yerin engebeli olması ve GPS modülünün hassas konum değeri verememesinden dolayı sonuçlar istenen değer etrafinda salınım yaptığı görülmektedir.

\section{SONUÇ VE TARTIŞMA (CONCLUSION AND DISCUSSION)}

$\mathrm{Bu}$ çalışmada düşük maliyetli sensörler kullanılarak bir aracın varış noktasına otonom bir şekilde gidilmesi üzerine çalışılmış ve başarılmıştır. Bunun için, GPS modülü, dijital pusula sensörü, mikrodenetleyici ve birde RC araç şase ve motorları kullanılmıştır. Mikrodenetleyiciye yüklenen GNK sistemi sayesinde İKA yardımsız bir şekilde hedef noktaya varabilmiştir. Daha hassas sonuçlar alabilmek için yüksek doğrulukta GPS modülü, IMU gibi cihazlarla desteklenmeli ve gelişmiş kontrol yapıları ile kontrolü gerçekleştirilmelidir. 


\section{KAYNAKLAR (REFERENCES)}

[1] Bruch H, Gilbreath G. A. (2002). Muelhauser J. W. and lum J. Q., Accurate waypoint navigation using non-differential GPS, Technical Report ADA422034. Space and naval warfare systems center, San Deigo, California.

[2] Bok -Joong Yoon, Myung-Wook Park and Jung-Ha Kim, (2006). UGV (Unmanned Ground Vehicle) Navigation using GPS and Compass, in Proceedings of SICEICASE, pp. 3621- 3625.

[3] Bok-Joong Yoon, Jung-Hun Na, Jung-Ha Kim, (2007). Navigation method using multi-sensor for UGV (Unmanned Ground Vehicle), Control, Automation and Systems. ICCAS '07. International Conference on, vol., no., pp.853,856.

[4] Puls T. (2009). GPS-based Position Control and Way-point Navigation System for Quadrocopters, In proceeding of: IEEE/RSJ International Conference on Intelligent Robots and Systems. St. Louis, MO, USA.

[5] Sethu S., Iyer S., Sandeep N.R., G.S.P. (2013). A facile approach to GPS navigation in unmanned ground vehicles, Advances in Technology and Engineering (ICATE), 2013 International Conference on , vol., no., pp.1,6.

[6] Wikipedia. (2014). http://en.wikipedia.org/wiki/Inertial_measurement_unit

[7] K. Kerimoğlu. (2011). Sabit kanatlı bir insansız hava aracı için düşük bütçeli otopilot sistemi tasarımı. Master thesis, TOBB Ekonomi ve Teknoloji Üniversitesi

[8] Wikipedia. 2014. http://en.wikipedia.org/wiki/GNC_(store) , 15.09.2014

[9] Fossen T.I (2011). Handbook of Marine Craft Hydrodynamics and Motion Control.John Wiley \& Sons Ltd.

[10] Jensen Marius T., "Waypoint-Following Guidance Based on Feasibility Algorithms". (Institutt for teknisk kybernetikk). Master's thesis, NTNU, Norway.

[11] Wikipedia. (2014). http://www.nrec.ri.cmu.edu/projects/safeguarding/application/, 15.09.2014

[12] Gupte, S., Mohandas, P.IT.; Conrad, J.M. (2012). A survey of quadrotor Unmanned Aerial Vehicles. Southeastcon, 2012 Proceedings of IEEE, vol., no., pp.1,6.

[13] Shumaker J. (2009), Interrupt Driven RS-232, Pulse Width Modulation, and Control Processing on a Single 8-bit PIC Chip, U.S. Army Research Laboratory ARL.

[14] Breivik M. (2003). Nonlinear Maneuvering Control of Underactuated Ships. Norwegian University Department of Cybernetic, Master's thesis, NTNU, Norway.

[15] Çayıroğlu İ. (2014). Kalman Filter and a Navigation Application. http://www.ibrahimcayiroglu.com/Dokumanlar/Makale_BilgiPaylasim/2012-2Kalman_Filtresi_Ve_Bir_Navigasyon_Uygulamasi.pdf.) , 15.09.2014

[16] Mau S. (2005). What is the Kalman Filter and How can it be used for Data Fusion?

[17] G. Bishop and G. Welch. (2001). An introduction to the Kalman filter, in SIGGRAPH Course Notes, Los Angeles, CA, pp. 1-81.

[18] Jorge A., Jose M. S., Pascual C., Juan F. C.,Ivan F. M., Carol M., Miguel O., (2009), "Visual 3-D SLAM from UAV", Intelligent Robot Systems. 